\title{
Radiological Outcome of Cotrel-Dubousset Instrumentation in Nineteen Patients with Adolescent Idiopathic Scoliosis
}

\author{
Murat Çalbıyık ${ }^{1}$ \\ 1 Hitit University Medicine Faculty Department of Orthopaedic and Traumatology Çorum/Turkey \\ Received: 22 May 2017, Accepted 25 July 2017, Published online: 28 August 2017 \\ (C) Ordu University Institute of Health Sciences, Turkey, 2017
}

\begin{abstract}
Objective: Adolescent idiopathic scoliosis is a progressive type of scoliosis that may lead to permanent deformity unless prevented and treated effectively. To present radiological outcome of patients with adolescent idiopathic scoliosis treated with the Cotrel-Dubousset $(\mathrm{CD})$ instrumentation in our clinic.

Methods: This was a prospective follow-up study of 19 patients ( 8 males, 11 females; mean age 18.5 years; age range 12-43 years) who underwent CD instrumentation for late onset idiopathic scoliosis. The CD instrumentation and posterior spinal fusion was performed using the standard technique through either anterior or posterior approach. On average, 13.52 vertebrae (range, 8-16) were included in the spinal fusion. The mean postoperative follow-up duration was 18 months (2-32 months).

Results: Cobb angle on frontal plane was corrected $47.74 \% \pm 21.73 \%$ at thoracic region and $34.52 \% \pm 15.96 \%$ at lumbar region. On sagittal plane, the percentage of correction was $28.61 \% \pm 20.91 \%$ on thoracic kyphosis angle and $38.96 \% \pm 29.73 \%$ lumbar lordosis angle. In general, physiological sagittal contour of spine was obtained in $49.2 \%$ of patients after CD instrumentation. The most common postoperative complications were hook dislocation $(n=8)$, bending and dislocation of screw $(n=7)$, broken lamina and pedicule $(n=5)$, and infection $(n=3)$, all of which were effectively treated.
\end{abstract}

Conclusion: CD instrumentation effectively corrects the late onset idiopathic scoliosis if it is performed after a proper preoperative planning.

Key words: Curl-up exercise, abdominal muscles, sternocleidomastoid, electromyography.

Address for correspondence/reprints:

Murat Çalbıyık

Telephone number: +905327698962

E-mail:

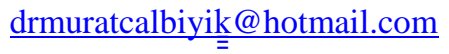

DOI: $10.19127 / \mathrm{mbsjohs.315163}$

\section{Introduction}

Late onset or adolescent idiopathic scoliosis is the most common spinal deformity in adolescents with an overall prevalence of $0.47-5.2 \%$ (Konieczny et al., 2013). It is characterized by a lateral deviation of the spine with unknown etiology, and defined as a spinal curve greater than $10^{\circ}$ detected by Cobb method (Cobb, 1948; Shindle et al., 2006). In severe cases, it is associated with severe pain, cardiopulmonary compromise, and social isolation (Weiss et al., 2016). Adolescent idiopathic scoliosis is a progressive type of scoliosis that may lead to permanent deformity unless prevented and treated effectively. Its treatment includes exercise, rehabilitation, and surgery (Weiss and Goodall, 2008). For optimal management, it is important to distinguish the adolescent idiopathic scoliosis from early-onset scoliosis, which occur before the age of 
10 and has a higher morbidity and mortality rate (Cunin, 2015; Weiss et al., 2016). The goal in scoliosis surgery is to reduce curvature and to create a stable framework on which vertebral fusion can occur (Gunnoe, 1990). Various instrumentation systems are currently utilized for posterior fusion in adolescent idiopathic scoliosis, such as Harrington rods, Universal Spine System instrumentation, the Cotrel-Dubousset (CD) instrumentation, and allpedicle screw constructs (Remes et al., 2004; Lykissas et al., 2013). Among these systems, CD instrumentation, which has been used for almost 30 years, is a rigid system of immobilization and allows the most effective correction for all kinds of spinal deformities (Cotrel and Dubousset, 1984; Dubousset and Cotrel, 1991). In comparison to other instrumentation techniques, CD instrumentation has been shown to provide higher degree of correction in the coronal and sagittal planes (Lykissas et al., 2013). Therefore, CD instrumentation became the most preferred technique in the operative treatment of adolescent idiopathic scoliosis. However, some mid- and long-term studies reported higher rate of complications and revision surgery associated with CD instrumentation (Helenius et al., 2003; Lykissas et al., 2013). Therefore, there is still a need for more experience with $\mathrm{CD}$ instrumentation to decide on the best technique for surgical treatment of adolescent idiopathic scoliosis.

In this study, we aimed to present radiological outcome of 19 patients with adolescent idiopathic scoliosis treated with CD instrumentation in our clinic.

\section{Methods}

\section{Study design and population}

This was a prospective follow-up study of 19 patients ( 8 males, 11 females; mean age 18.5 years; age range 12-43 years) who underwent $C D$ instrumentation for late onset idiopathic scoliosis in the Clinics of Orthopedic Surgery of SSK Okmeydani Hospital. None of the patients had received any treatment for scoliosis before applying to our clinic. On clinical and radiological assessment none of the patients had congenital, neuromuscular, or similar primary etiology for scoliosis.

\section{Surgical procedure}

The $C D$ instrumentation and posterior spinal fusion was performed using the standard technique through either anterior or posterior approach (Cotrel and Dubousset, 1984). On average, 13.52 vertebrae (range, 8-16) were included in the spinal fusion. All patients received autologous blood with or without cell saver, and were given intravenous cephalosporin during the operation and for 72 hours postoperatively for prophylaxis. A wake-up test was performed to check the intraoperative neurology after the insertion of the vertical rod on the concave side. All patients were mobilized in seven to ten days after the operation, and discharged after 15 days.

\section{Outcome measures}

The patients were evaluated at postoperative 1, 3, 6,12 , and 24 months. In each postoperative visit, the following data were recorded: subjective complaints, physical examination of scoliosis, asymmetry, rib hump, and change in gravity line. On the frontal and lateral radiographs of the spine, the Cobb angles at thoracic and lumbar regions, thoracic kyphosis, lumbar lordosis, and angulation at thoracolumbar junction were measured.

\section{Statistical analysis}

Study data were summarized using descriptive statistics (e.g., mean, standard deviation, frequency and percentage). For paired comparisons, Wilcoxon signed tank test was used. Statistical level of significance was set to $\mathrm{p}<0.05$.

\section{Results}

The clinical characteristics of patients were summarized in Table 1. According to starting age of scoliosis, 13 patients had adolescent, 5 had juveline, and 1 had infantile idiopathic scoliosis. On radiological assessment, majority of patients had either type $2(n=10)$ or type $4(n=6)$ idiopathic scoliosis according to King Classification (King et al., 1983). In terms of maturity, 6 males $(75 \%)$ had secondary sex characters, and 9 females $(81.8 \%)$ had menarche. The Risser sign, which is an indirect measure of skeletal maturity, revealed that most of the patients had either Grade $4(n=13)$ or Grade 5 $(\mathrm{n}=5)$ maturity, which correspond to an almost cessation of growth and end of growth, respectively (Risser, 1958).

The evaluation of the position of gravity center with respect to intergluteal line showed that gravity line passes exactly through the crease in 10 patients $(52.6 \%)$, which indicates a balanced curvature, while there was $1-3 \mathrm{~cm}$ deviation in seven patients $(36.8 \%)$ and more than three $\mathrm{cm}$ deviation in two patients $(10.5 \%)$. According to radiological evaluation, one patient had flexible thoracic lordosis, one had thoracic kyphosis, three had double major scoliosis, six had thoracolumbar scoliosis, and eight had rigid thoracic lordosis (Table 1). 
Table 1. Demographic and clinical characteristics of study patients

\begin{tabular}{llr}
\hline Parameters & & Result $(\mathrm{n}=19)$ \\
$\mathrm{n}(\%)$
\end{tabular}

a Grade 3: the ilium (bone) is calcified at a level of 75\% corresponding to the slowing of growth. Grade 4: the ilium (bone) is calcified at a level of $100 \%$ corresponding to an almost cessation of growth. Grade 5: the ilium (bone) is calcified at a level of $100 \%$ and the iliac apophysis is fused to iliac crest corresponding to the end of growth.

b Type 1: an "S" shape deformity, in which both curves are structural and cross the central sacral vertical line (CSVL), with the lumbar curve being larger than the thoracic one. Type 2: an "S" shape deformity, in which both curves are structural and cross the CSVL, with the thoracic curve being larger or equal to the lumbar one. Type 3: major thoracic curve in which only the thoracic curve is structural and crosses the CSVL. Type 4: long "C" shape thoracic curve in which the fifth lumbar vertebra is centered over the sacrum and the forth lumbar vertebra is tilted into the thoracic curve.

\section{The spinal correction obtained by CD instrumentation}

The average postoperative follow-up duration was 18 months (2-32 months). After this period, the Cobb angle on frontal plane was corrected $47.74 \% \pm 21.73 \%$ at thoracic region and $34.52 \% \pm 15.96 \%$ at lumbar region. On sagittal plane, the percentage of correction was $28.61 \% \pm 20.91 \%$ on thoracic kyphosis angle and $38.96 \% \pm 29.73 \%$ lumbar lordosis angle. The overall percentage of patients having thoracic kyphosis angle within normal limits or $0-10^{\circ}$ deviation increased from $80 \%$ to $95 \%$ with CD instrumentation. Similarly, the rate of lumbar lordosis angle within normal limits or $0-10^{\circ}$ deviation increased from $59 \%$ to $79 \%$. However, the rate of thoracolumbar angle within normal limits or $0-10^{\circ}$ deviation decreased from $89 \%$ to $42 \%$ (Figure 1). In general, physiological sagittal contour of spine was obtained in $49.2 \%$ of patients after CD instrumentation. Sample radiographs of a patient before and after $\mathrm{CD}$ instrumentation were presented in Figure 2. 


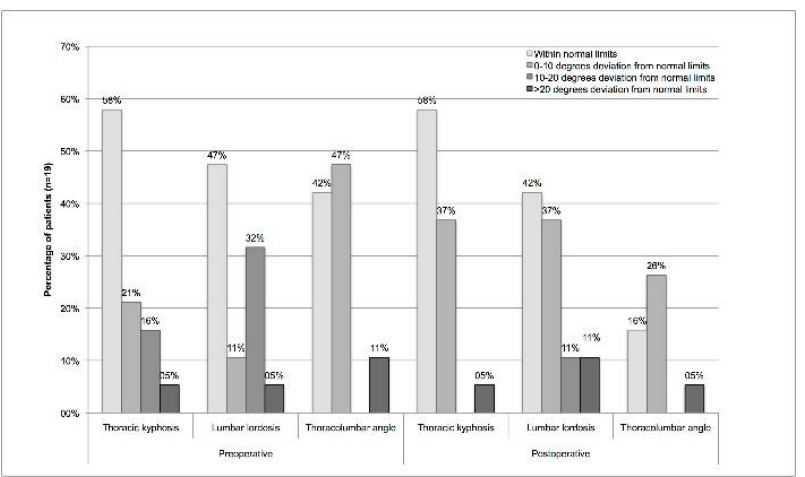

Figure 1. Distribution of patients with respect to sagittal angles before and after CD instrumentation $(n=19)$.
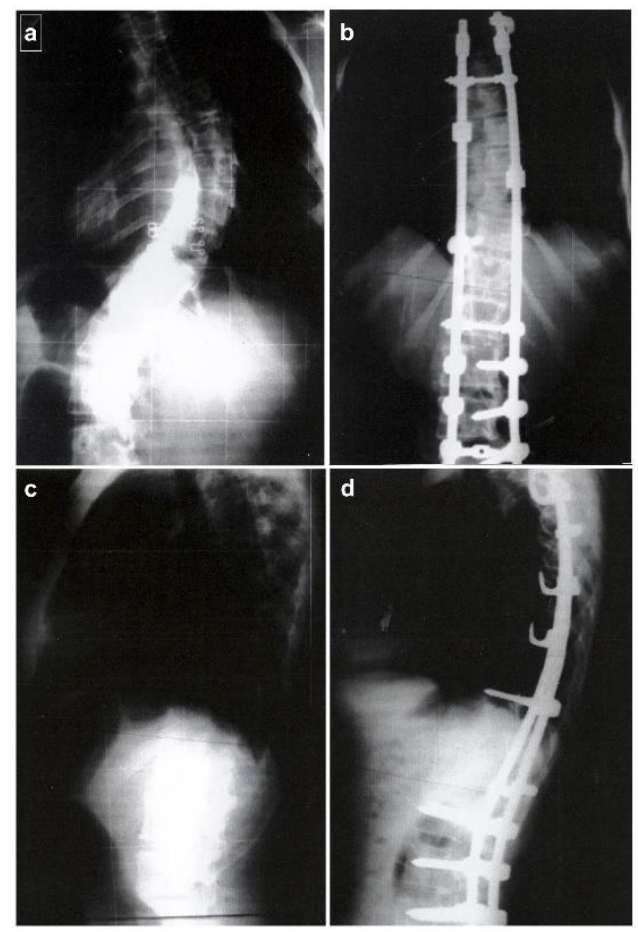

Figure 2. On the frontal plane radiograph of a patient with adolescent idiopathic scoliosis before CD instrumentation (a), the Cobb angles at thoracic and lumbar regions were $64^{\circ}$ and $50^{\circ}$, which decreased to $23^{\circ}$ and $16^{\circ}$ after CD instrumentation (b), respectively. On the sagittal plane radiograph of the same patient before $\mathrm{CD}$ instrumentation (c), thoracic kyphosis, lumbar lordosis, and thoracolumbar junction angles were $26^{\circ},-40^{\circ}$, and $0^{\circ}$, which changed to $12^{\circ},-7^{\circ}$, and $-7^{\circ}(\mathbf{d})$, respectively.
The degree of corrections on frontal plane obtained by $\mathrm{CD}$ instrumentation with respect to preoperative King classification was summarized in Table 2. Accordingly, the percentage of correction in the Cobb angles at thoracic and lumbar regions ranged between $11.9 \%$ and $64.1 \%$ and the degree of correction ranged between $10^{\circ}$ and $39.7^{\circ}$ on frontal plane, being statistically significant in King Type 2 and 4 scoliosis. The corrections that were obtained in bending Cobb angle were relatively lower (Table 2).

On sagittal plane radiographs, although angles of thoracic kyphosis, lumbar lordosis and thoracolumbar junction were corrected by $26.32 \%$ $48.95 \%$ after CD instrumentation, none of the corrections reached to the level of statistical significance (Table 3).

With respect to radiological type of scoliosis, the highest correction was obtained in thoralumbar scoliosis, particularly those with kyphosis in both frontal and sagittal planes (Tables 4 and 5).

At last follow-up radiographs, a $7.4^{\circ}$ of correction loss $(17.1 \%)$ in thoracic angle and $8.3^{\circ}$ of correction loss $(25.5 \%)$ in lumbar lordosis was recorded in King Type 2 curves (Table 6). The correction losses in the last follow-up were not statistically significant in other types of curves (Table 6).

The most common postoperative complications were hook dislocation $(\mathrm{n}=8)$, bending and dislocation of screw $(\mathrm{n}=7)$, broken lamina and pedicule $(n=5)$, and infection $(n=3)$, all of which were effectively treated. None of the patients developed neurological complications and pseudoarthrosis during follow-up. 
Table 2. The degree of corrections in the spine obtained by CD instrumentation on frontal plane radiographs with respect to preoperative King classification

\begin{tabular}{|c|c|c|c|c|c|c|c|c|c|}
\hline \multicolumn{2}{|c|}{ King Classification } & $\begin{array}{l}\text { Preoperative } \\
\text { Cobb angle }\end{array}$ & $\begin{array}{l}\text { Postoperative } \\
\text { Cobb angle }\end{array}$ & $\begin{array}{l}\text { Degree of } \\
\text { correction }\end{array}$ & $\begin{array}{c}\text { Percentage } \\
\text { of correction } \\
\% \\
\end{array}$ & $\mathrm{p}$ & $\begin{array}{c}\text { Preoperative } \\
\text { bending Cobb } \\
\text { angle }\end{array}$ & $\begin{array}{l}\text { Percentage of } \\
\text { correction } \%\end{array}$ & $\mathrm{p}$ \\
\hline \multirow{2}{*}{$\begin{array}{l}\text { Type } 1 \\
(\mathrm{n}=1)\end{array}$} & Thoracic & $84^{\circ}$ & $74^{\circ}$ & $10^{\circ}$ & 11.9 & - & $74^{\circ}$ & 11.9 & - \\
\hline & Lumbar & $100^{\circ}$ & $82^{\circ}$ & $18^{\circ}$ & 18.0 & - & $88^{\circ}$ & 12.0 & - \\
\hline \multirow[t]{2}{*}{$\begin{array}{l}\text { Type } 2 \\
(n=10)\end{array}$} & Thoracic & $75.6^{\circ} \pm 18.52^{\circ}$ & $43.4^{\circ} \pm 17.19^{\circ}$ & $34.3^{\circ} \pm 10.1^{\circ}$ & $44.42 \pm 17.76$ & $\begin{array}{l}0.0 \\
51\end{array}$ & $60.8^{\circ} \pm 22.5^{\circ}$ & $20.98 \pm 12.67$ & $\begin{array}{c}0.00 \\
5\end{array}$ \\
\hline & Lumbar & $49.2^{\circ} \pm 11.18^{\circ}$ & $31.0^{\circ} \pm 10.74^{\circ}$ & $17.9^{\circ} \pm 9.24^{\circ}$ & $36.14 \pm 15.78$ & $\begin{array}{c}0.0 \\
51\end{array}$ & $30.9^{\circ} \pm 12.31^{\circ}$ & $36.72 \pm 20.83$ & $\begin{array}{c}0.00 \\
5\end{array}$ \\
\hline \multirow[t]{2}{*}{$\begin{array}{l}\text { Type } 3 \\
(n=2)\end{array}$} & Thoracic & $66.0^{\circ} \pm 4.24^{\circ}$ & $31.0^{\circ} \pm 5.66^{\circ}$ & $35.0^{\circ} \pm 1.42^{\circ}$ & $53.20 \pm 5.52$ & $\begin{array}{l}0.1 \\
79\end{array}$ & $56.0^{\circ} \pm 18.38^{\circ}$ & $15.18 \pm 22.45$ & $\begin{array}{c}0.31 \\
7\end{array}$ \\
\hline & Lumbar & - & - & - & - & - & - & - & - \\
\hline \multirow[t]{2}{*}{$\begin{array}{l}\text { Type } 4 \\
(n=6)\end{array}$} & Thoracic & $65.83^{\circ} \pm 27.64^{\circ}$ & $\begin{array}{c}26.17^{\circ} \pm 21.12 \\
\circ\end{array}$ & $\begin{array}{c}39.7^{\circ} \pm 17.9 \\
3^{\circ}\end{array}$ & $64.1 \pm 20.72$ & $\begin{array}{l}0.0 \\
27\end{array}$ & $40.83^{\circ} \pm 30.16^{\circ}$ & $40.16 \pm 22.94$ & $\begin{array}{c}0.02 \\
8\end{array}$ \\
\hline & Lumbar & - & - & - & - & - & - & - & - \\
\hline
\end{tabular}

Table 3. The degree of corrections in the spine obtained by CD instrumentation on sagittal plane radiographs with respect to preoperative King classification

\begin{tabular}{llcccc} 
King Classification & Preoperative & Postoperative & $\begin{array}{c}\text { Degree of } \\
\text { correction }\end{array}$ & $\begin{array}{c}\text { Percentage of } \\
\text { correction } \%\end{array}$ \\
\hline Type 1 & TK & $48^{\circ}$ & $18^{\circ}$ & $30^{\circ}$ & - \\
$(\mathrm{n}=1)$ & LL & $11^{\circ}$ & $0^{\circ}$ & $11^{\circ}$ & - \\
& TL & $65^{\circ}$ & $56^{\circ}$ & $9^{\circ}$ & - \\
\hline Type 2 & TK & $31.4^{\circ} \pm 10.02^{\circ}$ & $30.2^{\circ} \pm 8.2^{\circ}$ & $8.2^{\circ} \pm 6.37^{\circ}$ & $26.32 \pm 16.60$ \\
$(\mathrm{n}=10)$ & LL & $-38.6^{\circ} \pm 22.27^{\circ}$ & $-27.4^{\circ} \pm 23.89^{\circ}$ & $-14.2^{\circ} \pm 15.31^{\circ}$ & $34.39 \pm 26.32$ \\
& TL & $-3.6^{\circ} \pm 9.83^{\circ}$ & $-0.4^{\circ} \pm 5.58^{\circ}$ & $7^{\circ}$ & 0.953 \\
\hline Type 3 & TK & $24.0^{\circ} \pm 14.14^{\circ}$ & $24.5^{\circ} \pm 0.7^{\circ}$ & $9.5^{\circ} \pm 0.71^{\circ}$ & $48.95 \pm 31.79$ \\
$(\mathrm{n}=2)$ & LL & $-25.0^{\circ} \pm 14.14^{\circ}$ & $-19.0^{\circ} \pm 19.97^{\circ}$ & $-6.0^{\circ} \pm 2.83^{\circ}$ & $32.38 \pm 29.63$ \\
& TL & $-2.5^{\circ} \pm 3.54^{\circ}$ & $1.0^{\circ} \pm 2.83^{\circ}$ & $4.5^{\circ}$ & 0.654 \\
\hline Type 4 & TK & $31.3^{\circ} \pm 24.3^{\circ}$ & $34.8^{\circ} \pm 16.99^{\circ}$ & $8.5^{\circ} \pm 9.35^{\circ}$ & 0.179 \\
$(\mathrm{n}=6)$ & LL & $-34.0^{\circ} \pm 17.88^{\circ}$ & $-23.5^{\circ} \pm 13.47^{\circ}$ & $12.83^{\circ} \pm 13.99^{\circ}$ & $3.99 \pm 19.52$ \\
& TL & $-43.0^{\circ} \pm 12.97^{\circ}$ & $-3.33^{\circ} \pm 5.20^{\circ}$ & $5.7^{\circ}$ & 0.654 \\
\hline
\end{tabular}

$\mathrm{TK}$, thoracic kyphosis; LL, lumbar lordosis; TL, thoracolumbar juntion.

Table 4. The degree of corrections in the spine obtained by CD instrumentation on frontal plane radiographs with respect to type of scoliosis

\begin{tabular}{|c|c|c|c|c|c|c|}
\hline & & $\mathrm{n}$ & $\begin{array}{l}\text { Preoperative } \\
\text { Cobb angle }\end{array}$ & $\begin{array}{c}\text { Postoperative } \\
\text { Cobb angle }\end{array}$ & $\begin{array}{l}\text { Degree of } \\
\text { correction }\end{array}$ & $\begin{array}{l}\text { Percentage of } \\
\text { correction } \%\end{array}$ \\
\hline Flexible thoracic lordosis & & 1 & $68^{\circ}$ & $41^{\circ}$ & $25^{\circ}$ & 36.8 \\
\hline Rigid thoracic lordosis & & 8 & $69.5^{\circ} \pm 9.43^{\circ}$ & $32.6^{\circ} \pm 6.32^{\circ}$ & $36.9^{\circ} \pm 8.42^{\circ}$ & $47.53 \pm 18.46$ \\
\hline Thoracic kyphosis & & 1 & $103^{\circ}$ & $72^{\circ}$ & $31^{\circ}$ & 30.1 \\
\hline \multirow[t]{2}{*}{ Thoracolumbar scoliosis } & Kyphosis & 2 & $40.0^{\circ} \pm 25.16^{\circ}$ & $10.5^{\circ} \pm 10.61^{\circ}$ & $29.5^{\circ} \pm 14.83^{\circ}$ & $77.7 \pm 12.30$ \\
\hline & Lordosis & 4 & $78.75^{\circ} \pm 14.74^{\circ}$ & $34.0^{\circ} \pm 21.46^{\circ}$ & $44.75^{\circ} \pm 16.72^{\circ}$ & $57.3 \pm 21.91$ \\
\hline \multirow[t]{2}{*}{ Double major } & First curve & \multirow{2}{*}{3} & $81.7^{\circ} \pm 27.57^{\circ}$ & $61.0^{\circ} \pm 21.81^{\circ}$ & $20.7^{\circ} \pm 13.61^{\circ}$ & $25.13 \pm 11.56$ \\
\hline & Second curve & & $71.3^{\circ} \pm 29.01^{\circ}$ & $48.3^{\circ} \pm 30.37^{\circ}$ & $23.0^{\circ} \pm 7.81^{\circ}$ & $35.9 \pm 15.48$ \\
\hline
\end{tabular}


Table 5. The degree of corrections in the spine obtained by $\mathrm{CD}$ instrumentation on sagittal plane radiographs with respect to type of scoliosis

\begin{tabular}{|c|c|c|c|c|c|c|c|c|c|c|c|c|c|c|}
\hline & & \multirow[b]{2}{*}{$\mathrm{n}$} & \multicolumn{3}{|c|}{ Preoperative } & \multicolumn{3}{|c|}{ Postoperative } & \multicolumn{3}{|c|}{$\begin{array}{l}\text { Degree of } \\
\text { correction }\end{array}$} & \multicolumn{3}{|c|}{$\begin{array}{c}\text { Percentage of } \\
\text { correction }\end{array}$} \\
\hline & & & TK & LL & $\mathrm{TL}$ & TK & LL & $\mathrm{TL}$ & TK & LL & $\mathrm{TL}$ & TK\% & LL\% & TL\% \\
\hline \multicolumn{2}{|c|}{ Flexible thoracic lordosis } & 1 & $34^{\circ}$ & $-39^{\circ}$ & $-12^{\circ}$ & $28^{\circ}$ & $-20^{\circ}$ & $-2^{\circ}$ & $6^{\circ}$ & $19^{\circ}$ & $10^{\circ}$ & 17.6 & 48.7 & 83.3 \\
\hline \multicolumn{2}{|c|}{ Rigid thoracic lordosis } & 8 & $27.75^{\circ} \pm 7.87^{\circ}$ & $-38.6^{\circ} \pm 15.78^{\circ}$ & $-4.1^{\circ} \pm 9.16^{\circ}$ & $28.9^{\circ} \pm 9.63^{\circ}$ & $-35.4^{\circ} \pm 16.25^{\circ}$ & $0.37^{\circ} \pm 5.18^{\circ}$ & $7.9^{\circ}$ & $7^{\circ}$ & $10.8^{\circ}$ & 28.4 & 18.2 & 60.6 \\
\hline \multicolumn{2}{|c|}{ Thoracic kyphosis } & 1 & $55^{\circ}$ & $-45^{\circ}$ & $-6^{\circ}$ & $32^{\circ}$ & $-28^{\circ}$ & $-3^{\circ}$ & $23^{\circ}$ & $17^{\circ}$ & $9^{\circ}$ & 41.8 & 37.8 & 50 \\
\hline \multirow[t]{2}{*}{$\begin{array}{l}\text { Thoracolumbar } \\
\text { scoliosis }\end{array}$} & $\begin{array}{l}\text { Kypho } \\
\text { sis }\end{array}$ & 2 & $52^{\circ} \pm 7.07^{\circ}$ & $-27.5^{\circ} \pm 28.99^{\circ}-$ & $-15.5^{\circ} \pm 20.51^{\circ}$ & $52.5^{\circ} \pm 3.54^{\circ}$ & $-31^{\circ} \pm 26.87^{\circ}$ & $-7^{\circ} \pm 4.24^{\circ}$ & $2.5^{\circ}$ & $3.5^{\circ}$ & $11.5^{\circ}$ & 4.8 & 12.7 & 54.8 \\
\hline & $\begin{array}{l}\text { Lordos } \\
\text { is }\end{array}$ & 4 & $21 \pm 23.24^{\circ}$ & $-37.3 \pm 14.32^{\circ}$ & $1.3 \pm 3.95^{\circ}$ & $26 \pm 12.83^{\circ}$ & $-19.8^{\circ} \pm 2.86^{\circ}$ & $-1.5^{\circ} \pm 5.07^{\circ}$ & $11.5^{\circ}$ & $17.5^{\circ}$ & $2.75^{\circ}$ & 57.8 & 46.9 & 25 \\
\hline \multicolumn{2}{|l|}{ Double major } & 3 & $3.3 \pm 13.75^{\circ}$ & $-10 \pm 41.04^{\circ}$ & $25 \pm 35.16^{\circ}$ & $26 \pm 6.93^{\circ}$ & $6.7^{\circ} \pm 14.2^{\circ}$ & $21^{\circ} \pm 31.8^{\circ}$ & $13^{\circ}$ & $26.7^{\circ}$ & $4.3^{\circ}$ & 39.4 & 25 & 19.2 \\
\hline
\end{tabular}

TK, thoracic kyphosis; LL, lumbar lordosis; TL, thoracolumbar juntion.

Table 6. The degree and percentage of correction loss at last follow-up radiographs with respect to preoperative King classification

\begin{tabular}{|c|c|c|c|c|}
\hline King Classification & & Degree of correction loss & Percentage of correction loss & $\mathrm{p}$ \\
\hline \multirow[t]{7}{*}{ Type 2} & Frontal plane & & & \\
\hline & Thoracic Cobbs & $7.4^{\circ}$ & $17.1 \%$ & 0.018 \\
\hline & Lumbar Cobbs & $7.1^{\circ}$ & $22.9 \%$ & 0.116 \\
\hline & Sagittal plane & & & \\
\hline & Thoracic kyphosis & $5.7^{\circ}$ & $18.9 \%$ & 0.179 \\
\hline & Lumbar lordosis & $8.3^{\circ}$ & $25.5 \%$ & 0.027 \\
\hline & Thoracolumbar junction & $4.4^{\circ}$ & - & 0.715 \\
\hline \multirow[t]{4}{*}{ Type 3} & Sagittal plane & & & \\
\hline & Thoracic kyphosis & $1.0^{\circ}$ & $4.1 \%$ & 0.179 \\
\hline & Lumbar lordosis & $4.0^{\circ}$ & $20.5 \%$ & 0.317 \\
\hline & Thoracolumbar junction & $2.0^{\circ}$ & - & 0.179 \\
\hline \multirow[t]{6}{*}{ Type 4} & Frontal plane & & & \\
\hline & Thoracolumbar Cobbs & $7.0^{\circ}$ & $26.8 \%$ & 0.345 \\
\hline & Sagittal plane & & & \\
\hline & Thoracic kyphosis & $6.7^{\circ}$ & $19.2 \%$ & 0.916 \\
\hline & Lumbar lordosis & $6.3^{\circ}$ & $26.8 \%$ & 0.345 \\
\hline & Thoracolumbar junction & $7.3^{\circ}$ & - & 0.294 \\
\hline
\end{tabular}

\section{Discussion}

Although there is still no consensus on the surgical technique for correction of adolescent idiopathic scoliosis, the $\mathrm{CD}$ instrumentation is the most preferred surgical treatment since its introduction in 1984 (Cotrel and Dubousset, 1984; Gunnoe, 1990). It has the advantage of rigid fixation and improved three-dimensional curve correction. In this prospective series of 19 patients with late onset idiopathic scoliosis, we obtained $47.74 \% \pm 21.73 \%$ correction on frontal plane and $28.61 \% \pm 20.91 \%$ correction in thoracic kyphosis and $38.96 \% \pm 29.73 \%$ in lumbar lordosis on sagittal plane with CD type instrumentation.

In a meta-analysis of 1613 patients from 27 studies, Lykissas et al. (2013) reported a correction of $40.3^{\circ}$ in thoracic curve and $37.2^{\circ}$ in lumbar curve on frontal plane, and a correction of $33.5^{\circ}$ in thoracic kyphosis and $46^{\circ}$ in lumbar lordosis on sagittal plane. Similarly, in our study, the degree of correction was $39.7^{\circ}$ in King Type 4 curves on frontal plane. Additionally, angles of thoracic kyphosis, lumbar lordosis and thoracolumbar junction were corrected by $26.32 \%-48.95 \%$ after CD instrumentation. The overall percentage of patients having thoracic kyphosis angle within normal limits or $0-10^{\circ}$ deviation increased from $80 \%$ to $95 \%$ with CD instrumentation. Similarly, the rate of lumbar lordosis angle within normal limits or $0-10^{\circ}$ deviation increased from $59 \%$ to $79 \%$. The overall correction degrees and percentages we obtained in our series were in similarity with previous metaanalysis (Lykissas et al., 2013).

The percentage of the correction in thoracic curve and lumbar lordosis was higher in King Type II and IV, and thoracolumbar scoliosis than the other types, as the correction in thoracic kyphosis was highest in Type III scoliosis. Similarly, in previous studies, the greatest correction in adolescent scoliosis was obtained by CD instrumentation in Type III and IV, and thoracolumbar curves (Wajanavisit et al., 2009; Puno et al., 1992).

Although none of the patients developed neurological complications and pseudoarthrosis 
during 18-month follow-up, three patients developed infection, which was treated effectively. We also encountered hook dislocation in eight patients, bending and dislocation of screw in seven patients, and broken lamina and pedicule in five patients, all of which may be due to our limited experience with $\mathrm{CD}$ instrumentation, which requires greater surgical skill than the Harrington rod with extended surgical time (Ameri et al., 2013).

The main limitation of the present study is the small sample size, which precludes us from reaching to a more definitive conclusion on the effectiveness and safety of CD type instrumentation in surgical correction of adolescent idiopathic scoliosis. Additionally, our limited experience with the surgical technique prevented us to obtain optimal outcome of CD instrumentation. Nevertheless, we think that our series will contribute to the literature of $\mathrm{CD}$ instrumentation and clinical practice of the technique.

Based on our experience with the present series of 19 patients, we have some suggestions for CD type instrumentation. For rigid type of scoliosis, anterior relaxation followed by posterior fusion and derotation maneuver increases degree of correction. Since the rods of CD instrumentation were not rigid enough, they should be bended during obtaining lumbar lordosis. The impaired balance, which is the most common complication of CD instrumentation in certain types of scoliosis, can be overcome by choosing correct level of fusion and avoiding excessive correction. The location of distal fusion should be determined by locating stable and neutral vertebrae and mobile disc space. In type 2 scoliosis, lumbar vertebrae should be included into fusion level in order to prevent decompensation in longterm.

\section{Conclusion}

In conclusion, $\mathrm{CD}$ instrumentation effectively corrects the late onset idiopathic scoliosis if it is performed after an extensive clinical and radiological assessment of spinal deviation preoperatively. We suggest that the high rates of correction loss and complications in our series are due to our inexperience with the technique and insufficient preoperative planning. We believe that with increased experience with $\mathrm{CD}$ type instrumentation and better surgical planning, the rates of complications and correction loss will be reduced and optimal correction will be obtained in cases with late onset idiopathic scoliosis.
Ethics Committee Approval: The requirement for the ethics committee approval was waived for the retrospective design and valid legal regulations at the time of the study.

Author Contributions: Idea- M.Ç; Design M.Ç; Supervision- M.Ç; Funding- M.Ç; Materials- M.Ç.; Data Collection/Data Process- M.Ç, Analyze or Comment- M.Ç, Literature Scanning- M.Ç.; Writer of Paper- M.Ç.; Critical Review- M.Ç.

Peer-review: Externally peer-reviewed.

Conflict of Interest: No conflict of interest was declared by the author.

\section{References}

Ameri E, Ghandhari H, Hesarikia H, Rasouli HR, Vahidtari H, Nabizadeh $\mathrm{N}$. Comparison of harrington rod and cotrel-dubousset devices in surgical correction of adolescent idiopathic scoliosis. Trauma Mon 2013;18(3):134-8.

Cobb JR. Outline for the study of scoliosis. Am Acad Orthop Surg Instr Course Lect 1948; 5:261-5.

Cotrel Y, Dubousset J. Nouvelle technique d'ostheosynthèse rachidienne sègmentaire par voie postèrieure. Rev Chir Orthop 1984; 70:48995.

Cunin V. Early-onset scoliosis: current treatment. Orthop Traumatol Surg Res 2015;101(1 Suppl): S109-18.

Dubousset J, Cotrel Y. Application technique of Cotrel-Dubousset instrumentation for scoliosis deformities. Clin Orthop Relat Res 1991; 264:103-10.

Gunnoe BA. Adolescent idiopathic scoliosis. Orthop Rev. 1990; 19(1):35-43.

Helenius I, Remes V, Yrjönen T, Ylikoski M, Schlenzka D, Helenius M, Poussa M. Harrington and Cotrel-Dubousset instrumentation in adolescent idiopathic scoliosis. Long-term functional and radiographic outcomes. J Bone Joint Surg Am 2003;85-A (12):2303-9.

King HA, Moe JH, Bradford DS, Winter RB. The selection of fusion levels in thoracic idiopathic scoliosis. J Bone Joint Surg Am 1983;65(9):1302-13.

Konieczny MR, Senyurt H, Krauspe R. Epidemiology of adolescent idiopathic scoliosis. J Chil Orthop 2013;7(1):3-9. 
Lykissas MG, Jain VV, Nathan ST, Pawar V, Eismann EA, Sturm PF, Crawford AH. Mid- to long-term outcomes in adolescent idiopathic scoliosis after instrumented posterior spinal fusion: a meta-analysis. Spine (Phila Pa 1976) 2013;38(2):E113-9.

Puno RM, Grossfeld SL, Johnson JR, Holt RT. Cotrel-Dubousset instrumentation in idiopathic scoliosis. Spine (Phila Pa 1976) 1992;17(8 Suppl): S258-62.

Remes V, Helenius I, Schlenzka D, Yrjönen T, Ylikoski M, Poussa M. Cotrel-Dubousset (CD) or Universal Spine System (USS) instrumentation in adolescent idiopathic scoliosis (AIS): comparison of midterm clinical, functional, and radiologic outcomes. Spine (Phila Pa 1976) 2004 Sep 15;29(18):2024-30.

Risser JC. The iliac apophysis; an invaluable sign in the management of scoliosis. Clinical Orthopaedics 1958; 11:111-9.

Shindle MK, Khanna AJ, Bhatnagar R, Sponseller PD. Adolescent idiopathic scoliosis: modern management guidelines. J Surg Orthop Adv 2006; 15(1):43-52.

Wajanavisit W, Woratanarat $\mathrm{P}$, Thiabratana $\mathrm{P}$, Woratanarat T, Laohacharoensombat W. A comparison between the Cotrel-Dubousset and the pedicle screw-plate instrumentations in the adolescent idiopathic scoliosis. J Med Assoc Thai 2009 ;92 Suppl5:S95-101.

Weiss HR, Goodall D. The treatment of adolescent idiopathic scoliosis (AIS) according to present evidence. A systematic review. Eur J Phys Rehabil Med 2008; 44:177-93.

Weiss HR, Karavidas N, Moramarco M, Moramarco K. Long-Term Effects of Untreated Adolescent Idiopathic Scoliosis: A Review of the Literature. Asian Spine J 2016;10(6):1163-9. 